\title{
Introducing Humans to the Extraterrestrials: the Pioneering Missions of the Pioneer and Voyager Probes
}

\author{
Klara Anna Capova ${ }^{1,2 *}$ \\ ${ }^{1}$ Department of Anthropology, Durham University, Durham, United Kingdom, ${ }^{2}$ The Pufendorf Institute for Advanced Studies, \\ Lund University, Lund, Sweden
}

This article gives a brief overview of how human life is represented on the 1972 Pioneer 10 and 1973 Pioneer 11 plaques and on the 1977 Voyager 1 and 2 Golden Records, sent on their journeys to deep space by the U.S. National Aeronautics Space Administration (NASA). Having left the boundaries of the Solar System and moving through interstellar space, the space probes still carry messages with information about their makers and their era. After a description of the two famous American interstellar messages, this article gives a basic introduction to their contents using some of the photographs available in the public domain. The overview includes the visual and audio part of the Voyager message and is

OPEN ACCESS

Edited by: Jessica K. Abbott, Lund University, Sweden

Reviewed by: William Lempert,

Bowdoin College, United States Danielle Briot, Observatoire de Paris, France

*Correspondence: Klara Anna Capova ka.capova@gmail.com

Specialty section: This article was submitted to Digital Impacts, a section of the journal Frontiers in Human Dynamics

Received: 25 May 2021 Accepted: 13 September 2021

Published: 18 October 2021

Citation:

Capova KA (2021) Introducing Humans to the Extraterrestrials: the Pioneering Missions of the Pioneer and Voyager Probes.

Front. Hum. Dyn 3:714616. doi: 10.3389/fhumd.2021.714616 focused around the questions for what types of information were included, what methods were used to communicate the information and how were humans introduced to the unknown receiver.

Keywords: NASA, pioneer, golden record, interstellar messages, anthropology of science, voyager

\section{THE PIONEERING MISSIONS OF THE PIONEER AND VOYAGER PROBES}

Human fascination with, and curiosity about, the yet unanswered question about whether we are the only life forms and the only intelligent species in the Universe has been puzzling generations of thinkers, scientists, and writers. Are we alone? Is there other life out there? If yes, what is it like? Is it humanoid? With the advent of the Space Age, era beginning in the form of the first space travel in 1957 (Sputnik 1) and the concurrent advancements in space technologies, it became more plausible for scientists to take on the age-old question and attempt to actively search for life beyond our planet. Among the first methods that were used was to send a message using either vehicles used for travelling in space or to transmit a signal via radio telescope.

In 1972, the National Aeronautics and Space Administration (NASA) launched the Pioneer 10 spacecraft on its mission to Jupiter, as NASA's first mission to the outer planets. Its twin, Pioneer 11, followed 1 year later. After successful exploration of the Jovian system, the Pioneers continued their journey to Saturn, Uranus and beyond, into deep space. The Voyagers were launched in 1977 with the primary mission objective to "extend the NASA exploration of the Solar System beyond the neighbourhood of the outer

Abbreviations: JPL, Jet Propulsion Laboratory; METI, Messaging Extraterrestrial Intelligence; NAIC, National Astronomy and ionosphere Centre; NASA, National Aeronautics Space Administration; SETI, Search for Extraterrestrial Intelligence. 
planets to the outer limits of the Sun's sphere of influence, and possibly beyond." ${ }^{\prime}$ Until 1998, when the Voyager two that travels at higher speed got ahead, Pioneer 10 held the primacy in being the most distant spacecraft from earth. Heading for the Aldebaran, in Taurus (The Bull) constellation, NASA estimates it will take Pioneer 10 over 2 million years to reach $i^{2}$.

The Pioneer and Voyager missions hold important positions in space exploration and together with science data delivered, they made many historic firsts such as the first Jupiter flyby (1973, Pioneer 10), the first Saturn flyby (1979, Pioneer 11), the first photograph of the whole Solar System (1990, Voyager 1), the famous Pale Blue Dot photo on which the earth appears as a bright pixel (1990, Voyager 1). In 2012, Voyager 1 became the first manmade object to have entered interstellar space.

Another thing makes those two space missions special: the messages mounted on the exterior of both Pioneers and Voyagers (Figure 2 and Figure 3). Alike in form, yet different in the volume of information provided, the task of these metal artefacts is to inform the receiver about the creators of the spacecraft. Beyond any doubt, the scientific team in charge of message development led by Carl Sagan embarked on a challenging endeavour. Together with the technological challenges, many questions arise. Firstly, how to represent our lifeforms to other imagined lifeforms, separated from us by time, space and biological and cultural factors beyond our imagination. What methods, channels to use? Secondly, an equally important question, namely to describe what human life is like. Who are we? What do we have in common? What is life on Earth like?

\section{THE INTERSTELLAR ARTEFACTS}

Now mostly referred to as the Pioneer Plaque, a small gold-anodised aluminium plate was mounted on each spacecraft. The inscriptions feature the nude figures of a human male and female along with several symbols that were designed to provide information about the origin of the spacecraft. Described by NASA as "a mark of Man," the plaque was authored by a small team consisting of astronomer and science populariser Carl Sagan and American astronomer and astrophysicist Frank Drake (NASA 1977). Drake, also known as the author of an equation which estimates the number of advanced civilisations in the Universe formulated in $1961^{3}$ and ${ }^{4}$ pioneered the use of radio telescopes in the Search for Extraterrestrial Intelligence (SETI) that started in the 1960s. Artist

\footnotetext{
${ }^{1}$ Source and more information on Voyager 1 and 2 missions is available from NASA Voyager Mission website: https://www.nasa.gov/mission_pages/voyager/ overview.

${ }^{2}$ Source and more information on Pioneer 10 and 11 missions is available from NASA AMES Missions Archive:https:/www.nasa.gov/centers/ames/missions/ archive/pioneer.html.

${ }^{3}$ The Drake equation is a probabilistic argument used to arrive at an estimate of the number of active, communicative extraterrestrial civilizations in the Milky Way galaxy. The Drake Equation estimates $\mathrm{N}$, the number of transmitting societies in the Milky Way galaxy.

${ }^{4}$ Opposite method to "messaging"-also referred to as METI (Messaging the Extraterrestrial Intelligence) - is the Search for Extraterrestrial Intelligence (SETI). SETI uses radio technology to monitor electromagnetic radiation for signs of transmissions from civilizations.
}

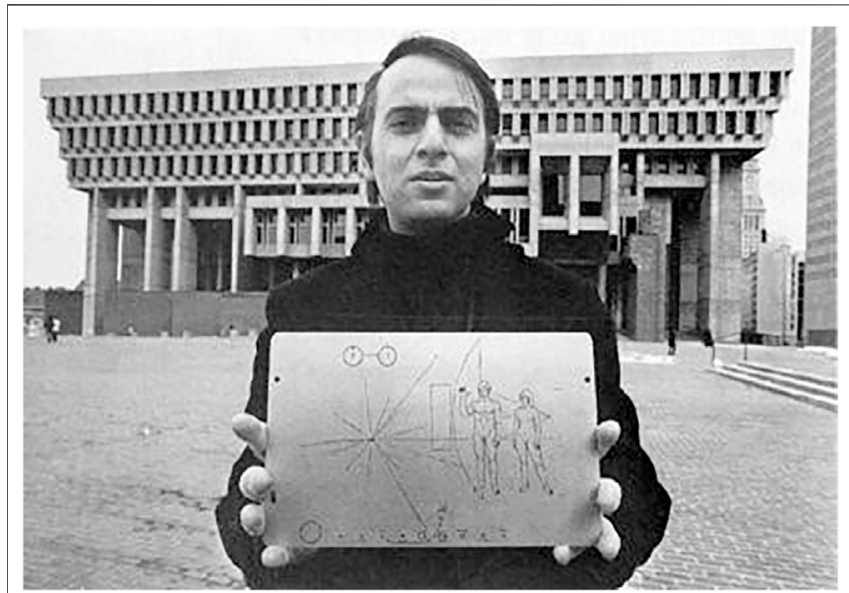

FIGURE 1 | Carl Sagan holding the Pioneer plate. Credit: NASA.

Linda Salzman Sagan, wife of Carl Sagan, created the artwork for the plaque.

Sagan, pictured below holding the Pioneer Plaque (Figure 1), later became chair of a committee that compiled a message that travelled to outer space aboard Voyager spacecrafts. Drake also remained involved in the Voyager committee. According to NASA's mission report, the history of the making of the Pioneer message was of short duration (NASA 1977):
"Dr. Sagan also was enthusiastic about the idea of a message on Pioneer. He and Dr. Drake designed a plaque, and Linda Salzman Sagan prepared artwork which was presented to NASA which accepted it for this first spacecraft from the Solar System into the Galaxy."

The plate, only fifteen by $23 \mathrm{~cm}$ big, presents five engraved diagrams as can be seen explained in Figure 2, informing about the existence of humankind and its location in our Galaxy. In the upper left corner of the plate, we see two connected circles that show a hyperfine transition of neutral hydrogen (used as a standard unit for measurements of time and distance). The radial diagram below is actually a map that gives the position of our Sun shown in relation to fourteen pulsars. Pulsars are fast rotating degenerated stars that emit regular pulses and hence are used as stellar beacons.

In the bottom part the planets of the Solar System are displayed, starting with the Sun on the very left. The line with the arrow points to the origin of the spacecraft from the third planet. The Pioneer spacecraft silhouette shown in the upper right part accompanies a couple of Earthlings with the male representative friendly greeting the inhabitants of other worlds. Located on the right is a small diagram that represents the binary equivalent of decimal eight. The "hydrogen wavelength multiplied by the binary number representing eight alongside the woman, gives her height," as explained in the NASA Pioneer mission report (NASA 1977). The same technical report also describes that the Pioneer plaque: "represents at least one intellectual cave painting, a mark of Man, that might survive not only all the caves on Earth, but also the Solar System itself. It is an interstellar stela that shows mankind possesses a spiritual insight beyond the material problems of the age of human emergence." 


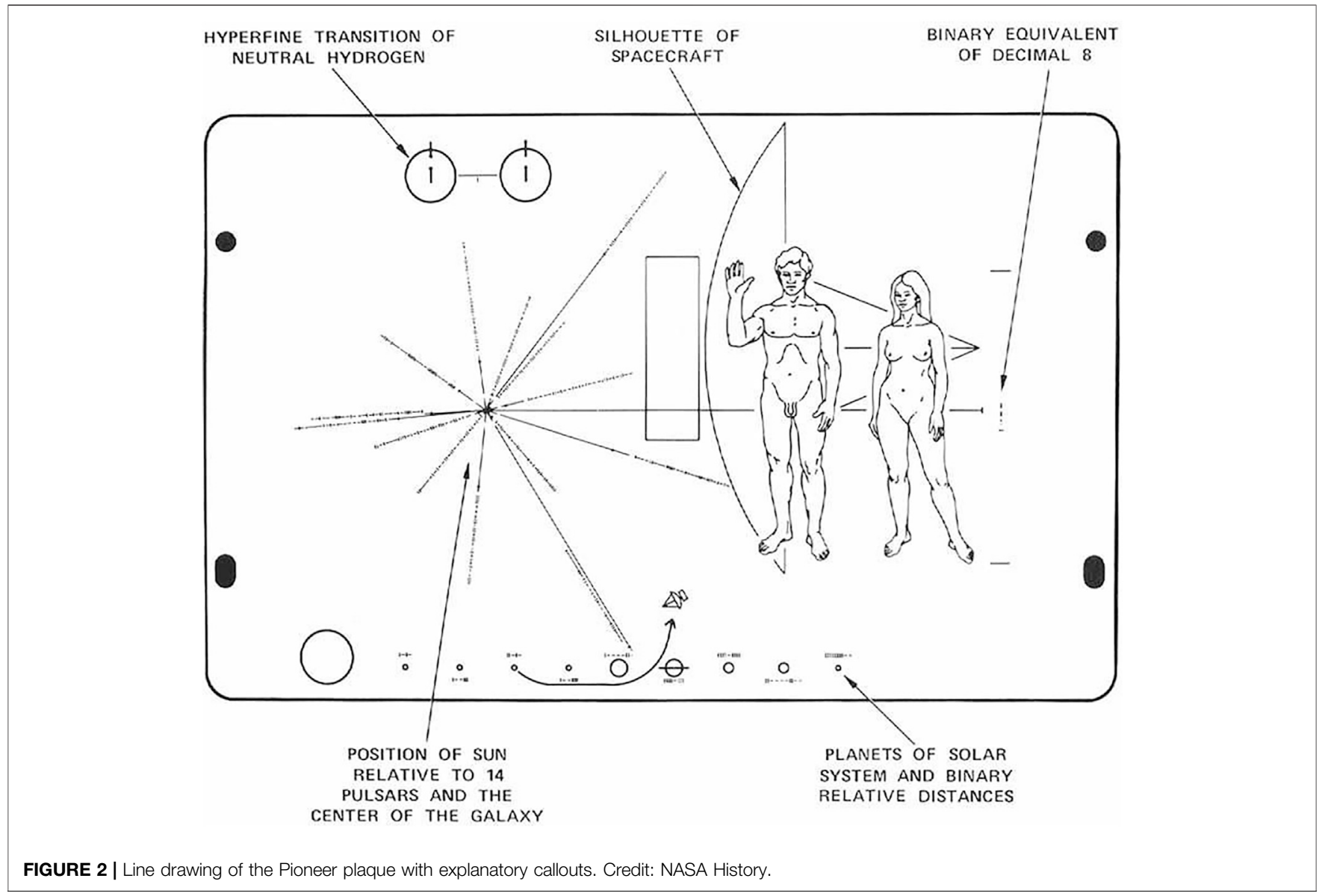

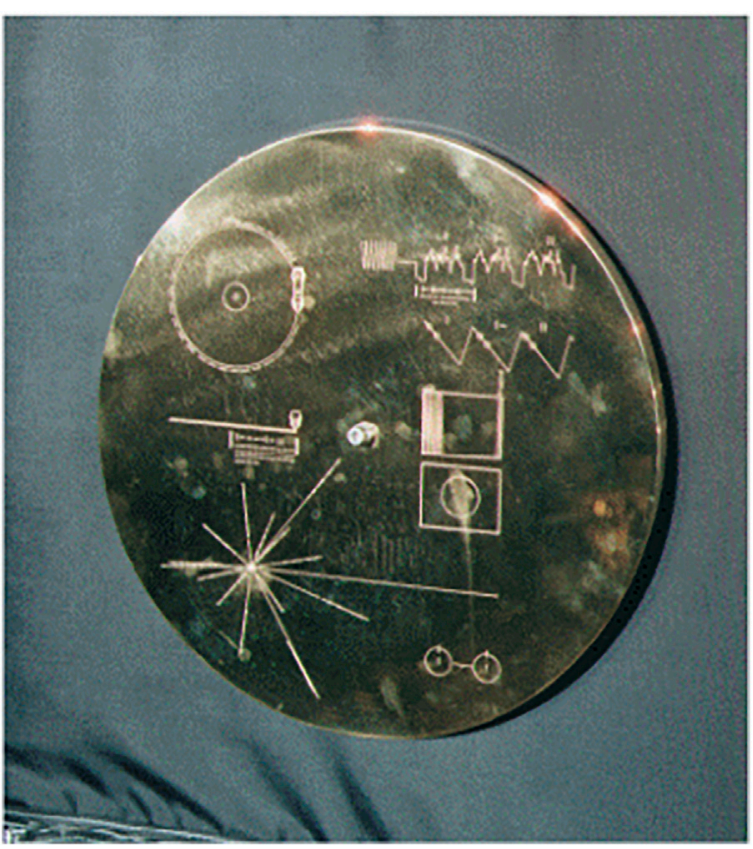

FIGURE 3 | The protective cover with instructions, mounted on Voyager spacecraft. Credit: NASA JPL.
Sagan himself said that the chances of a Pioneer spacecraft being detected are remote, but if it were to happen, would the recipients know what the engravings on the plaques represent or were meant to represent? Will they be able to make sense of a radial diagram, mysterious symbolism and a silhouette, and do we, natives of a culture that produced such a message, understand the meaning of Pioneer diagrams when presented to us without any prior knowledge of its intended meaning or further explanation? At first sight, the engraved plate may seem rather elementary, especially when served with the explanatory callouts. Yet there is a number of qualities and conditions that the receiver would have to possess to be able to find, read and understand such a message (Capova 2013).

Firstly, and it might be regarded as axiomatic, advanced technology and equipment is required to detect and intercept the Pioneer spacecraft. Secondly, eyes, or an organ of sight, is needed to recognise or see the engravings. Thirdly, and it may sound as an absurd statement, the receiver will have to be interested in reading such messages, be curious about what those engravings mean and be willing to attempt to unravel the meaning of symbols. Especially the science concepts, such as the hyperfine transition of neutral hydrogen, map of nearby pulsars and Solar System map, require having background in science, abstract thinking, intellectual curiosity, and creativity. These prerequisites reveal that science as "collective empiricism" that involves "investigators dispersed over continents and generations" (Daston and Galison 2007) is considered as an 
universal language; and hence it could be also the only language we would have in common with the (assumed) recipients of the message.

\section{THE VOYAGER'S MESSAGE IN A BOTTLE}

In 1977, the Voyager messages set off on their mission to explore the gas giants Jupiter and Saturn and later to continue towards the outermost edge of the Solar System. The record contents were created and assembled for NASA by a committee chaired by Sagan and the scientific team: Frank Drake, Ann Druyan, Timothy Ferris, Jon Lomberg, Linda Salzman Sagan. Drake is the author of some diagrams from the visual part, specifically of mathematical definitions. Lomberg, US space artist and designer, created the record's diagrams. International consultations have taken place to accomplish the objective.

While the Pioneer information plaque is composed of engraved symbols, the idea for Voyager was to include a comprehensive description of life on earth, not solely focused on humans but also giving the wider context. A combination of media, visual and audio, were included to portray the complexity and diversity of life on earth and to describe humans and their planet. The messages are in fact time capsules, intended for "future times and beings" as Carl Sagan said about the Voyagers (1978), in a sense immortal sentiment that we have left behind.

\section{PLAYING THE GOLDEN RECORD}

The Voyager message consists of a phonograph record with complex audio-visual information. The key to unlocking the message rests engraved on the protective aluminium jacket of the message, the interstellar envelope (Figure 3) where we can recognise the pulsar map and time reference diagram used for the Pioneer plaque. Six of the eight diagrams give instructions for how to assemble the phonograph and play the record (Figure 4). There is an outline of a cartridge with stylus using both side and front elevations. Once the phonograph has been assembled, using the record, a cartridge and a needle provided in the case, the next step for the receiver is to see the contents electronically placed on the record.

The gold-plated copper disk hidden under the cover, known as the Golden Record (Figure 5), has its contents divided into four sections:

- Scenes from Earth-118 images and diagrams about our species and our planet (including basic mathematical, chemical, and physical definitions).

- Greetings from Earth-spoken greetings from Earth-people in fifty-five languages and printed messages from US President Jimmy Carter and UN Secretary General Kurt Waldheim.

- Music from Earth-musical selections from different cultures and eras (27 audio recordings of Eastern and Western classics and a variety of ethnic music).

- Sounds of Earth-a variety of natural sounds (21 audio recordings of human activities, machines, and natural phenomena).

The Scenes from Earth comprise one hundred and eighteen pictures in total out of which seventeen are descriptive, black and white, two-dimensional diagrams created by the scientific team. The remaining pictures are colour photographs from various sources. If properly decoded and played, the first picture of the message, the "Calibration circle" appears. A simple, black and white line drawing of a circle, reproducing the shape of the record itself, is the encouraging sign that the message was decoded properly and the Scenes from Earth open. The introductory slide is followed by definitions of basic mathematical concepts, physical units and quantities, and two diagrams of "Solar system parameters" that show the Sun and (then) nine planets. The diagram is then followed by individual photographs of Solar System objects; Sun, Mercury, Mars (Figure 6), Earth (Figure 7), and Jupiter.

When examining the photographs, the viewers can see that explanatory symbols, e.g., mathematical definitions or chemical formulas, were inserted directly into the picture. For example, the photograph entitled "Egypt, Red Sea, Sinai Peninsula, and the Nile" on Figure 8 provides a description of the chemical composition of Earth's atmosphere. The top left tag shows that nitrogen $\left(\mathrm{N}_{2}\right)$ accounts for $78 \%$ of the atmosphere $\left(\mathrm{N}_{2} 78 / 100\right)$.

Subsequent to the astronomy basics are the definition of chemical units created by Drake. The models of chemical elements include: hydrogen $(\mathrm{H}$, the simplest and most abundant element in the Universe), carbon ( $\mathrm{C}$, occurs in all organic compounds), nitrogen $(\mathrm{N}$, a constituent of all living tissues), oxygen $(\mathrm{O}$, the most abundant element in the earth's crust). A model of phosphorus (P), an element that occurs commonly in inorganic phosphate rocks and as organic phosphates in all living cells, was also incorporated into the diagram. Why use chemistry? The chemical elements here demonstrate the basis of life because they in combinations constitute all matter. These elements are known as the fundamental building blocks of life. There is another crucial motive emerging from this pictorial sequence, and that is the description of humans as "carbon-based" life forms.

The two pictures of the DNA Structure (deoxyribonucleic acid) were created by Lomberg. The DNA molecule is associated with the transmission of genetic information and carries genetic instructions in all living things. Next picture shows the microscopic detail of cells and their division. It is followed by twenty images that describe human life on planet earth. Nine of the pictures document human anatomy, and are followed by reproduction and procreation: in other words, the story of life. ${ }^{5}$

${ }^{5}$ Due to copyright restrictions, only a subset of the images on the Golden Record is available for public display. The images that exist on The Golden Record but are copyrighted include Cells and cell division (Turtox/Cambosco), Anatomy (World Book), Human sex organs (Sinauer Associates, Inc.), Conception (Albert Bonniers; Forlag, Stockholm), Group of children (Ruby Mera, UNICEF), Family portrait (Nina Leen, Time, Inc.), Seashore (Dick Smith), Forest scene with mushrooms (Bruce Dale), Leaf (Arthur Herrick), Waterhole (South African Tourist Corp.), Jane Goodall and chimps (Vanne Morris-Goodall), Thailand craftsman (Dean conger), Elephant (Peter Kunstadter), Taj Mahal (David Carroll), Golden Gate Bridge (Ansel Adams), Train (Gordon Gahan), Toronto Airport (George Hunter), Radio telescope (Westerbork, Netherlands, James Blair), Sunset with birds (David Harvey), String Quartet (Quartetto Italiano, Phillips Recordings) amongst other. To preview the publicly available photographs, the reader is invited to visit the NASA JPL website: https://voyager.jpl.nasa.gov/golden-record/whats-on-therecord/images The entire visual contents of the Voyager Message has been published by Sagan in his 1978 book Murmurs of Earth. 


\section{EXPLANATION OF RECORDING COVER DIAGRAM}

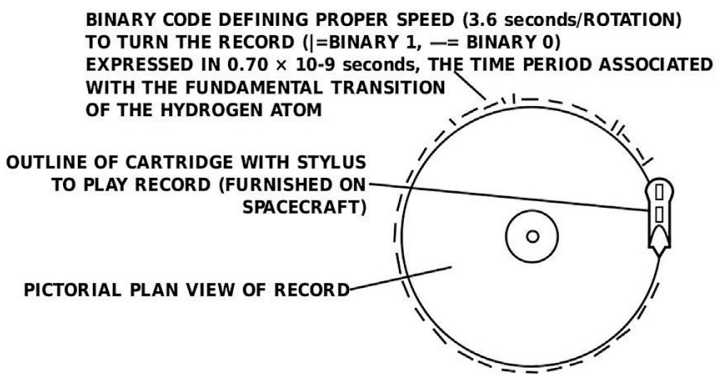

ELEVATION VIEW OF CARTRIDGE

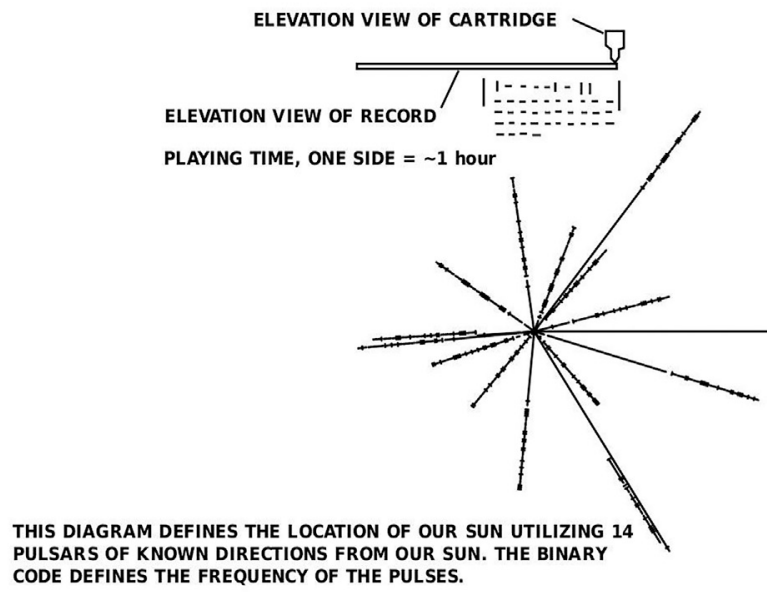

THE DIAGRAMS BELOW DEFINE THE VIDEO PORTION OF THE RECORDING

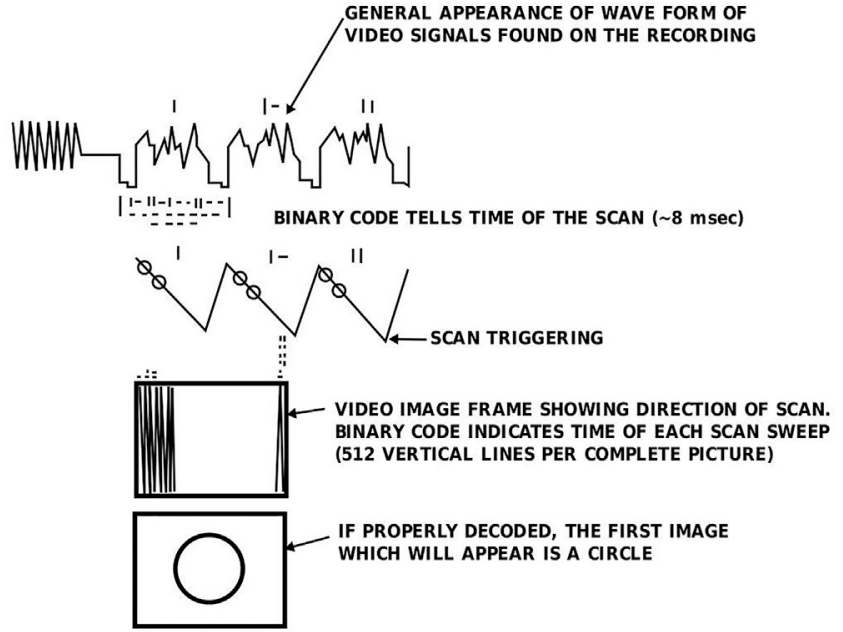

\section{LIFE CREATION: THE VOYAGER STORY}

The set of pictures dedicated to "life creation" shows cell division, human anatomy, and human sex organs. Human anatomy is illustrated using encyclopedic entries from the World Book encyclopedia (Sagan and Drake, 1975). The diagram of conception explains the size of sperm and shows how it penetrates the egg. The picture of "Fertilised ovum" shows the fertilised egg at two stages: one second, immediately after conception, and time until the first of cell division, indicated with the tags " $1 \mathrm{~s}$ " and " $43200 \mathrm{~s}$." The portrayals of conception and fertilisation are models that can be found in biology school books.

The viewers notice here that the visuals are presented in two forms. The first one is true, colour photographs that record the moment or events. The second one consists of schematic representations, black silhouettes on a white background based on the photographs (e.g., the Fetus and Silhouette, the Diagram of family ages). The explanatory labels and descriptions were inserted directly into the photographs such as height, mass (mathematical notations). All pictures are marked with numbers that show their order.
The representation of the foetus is also both symbolic and authentic; the diagram includes description of the foetus and its evolution in time and its growth, using numerical legends to indicate its development up to $5 \mathrm{~cm}$ in size. We can understand those images on two levels. Firstly, it describes that humans reproduce and secondly that humans comprehend and conceptualise the process of reproduction. By doing so, these pictures illustrate how science is done, communicated and visualised; science as a shared "collective empiricism" (Daston and Galison 2007).

The visual narrative of creation of human life consists of nine pictures. The preceding descriptive anatomical part includes eight pictures and presentes details of the bodily structure of humans. The "Diagram of male and female" is a black and white silhouette of a heterosexual couple holding hands surrounded by symbols indicating the sex, age, and height of the two figures. The female figure has a foetus in her womb. The purpose of the diagram is to underline the biological fact that people have children. The tags also tell us that male is $160 \mathrm{~cm}$ tall and 20 years old, while the female is $155 \mathrm{~cm}$ tall and of the same age. The image entitled "Birth" shows a surgeon wearing a surgical mask, assisting with the delivery. Here we can observe that 


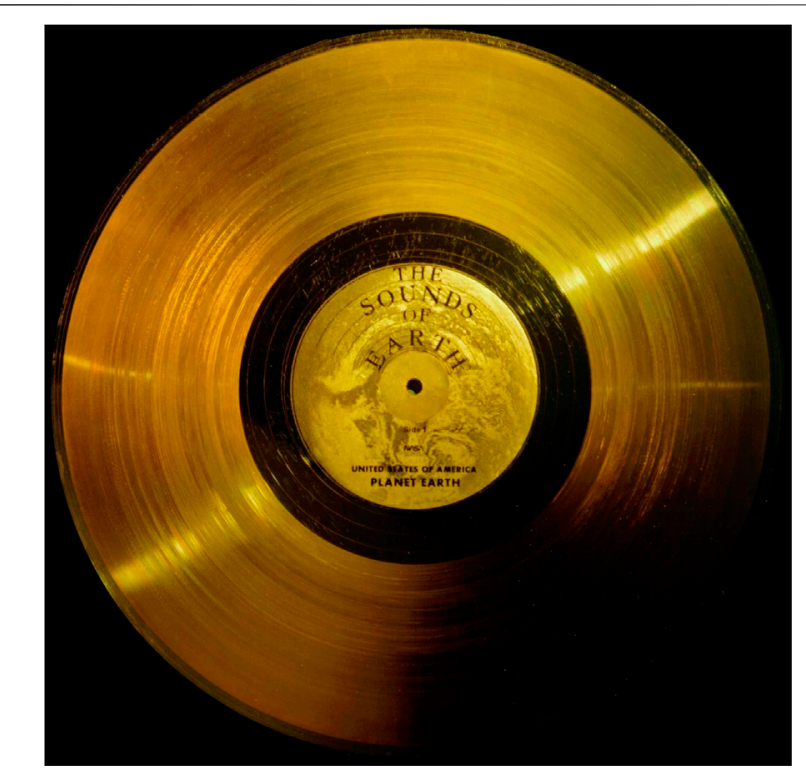

FIGURE 5 | The golden record. Credit: NASA.

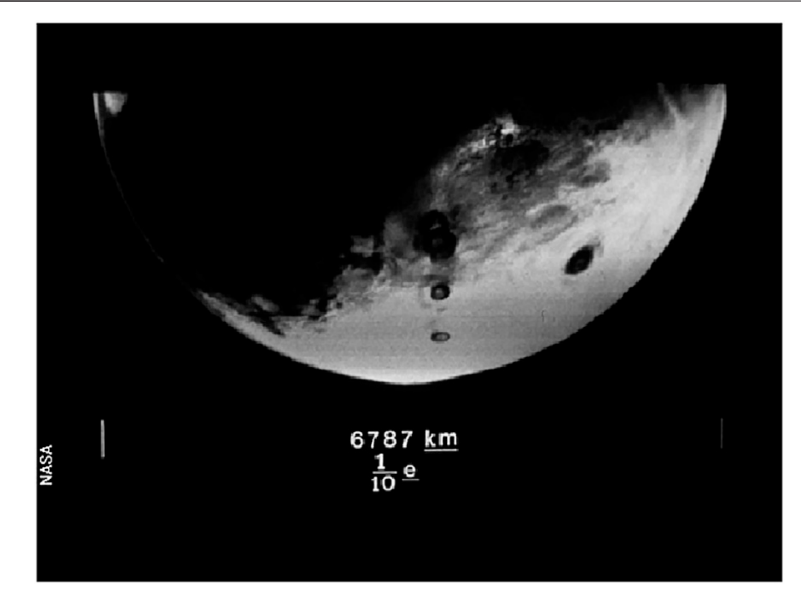

FIGURE 6 | Mars. Credit: NASA.

giving birth to a child at a hospital displayed here was considered the most common option in developed countries. The emphasis given on medical assistance during birth of a child is a traditional medical practice typical in the Western societies.

The further bond and care of mother for the child and the role of the father are documented in two pictures: Nursing Mother and Father and daughter (from Malaysia), both presenting another fact: parents care for their offspring. It is worth mentioning that there is a link between the picture of "Nursing mother" and one of the audio tracks. The recording features a crying baby and a mother's voice talking to the child yet the spoken language is English.

Succeeded to the life section are pictures that refer to family or community, It consists of five items-"Nursing mother," "Father and child," "Group of Children," "Diagram of family ages," and "Family portrait." On the representation of the family, we can

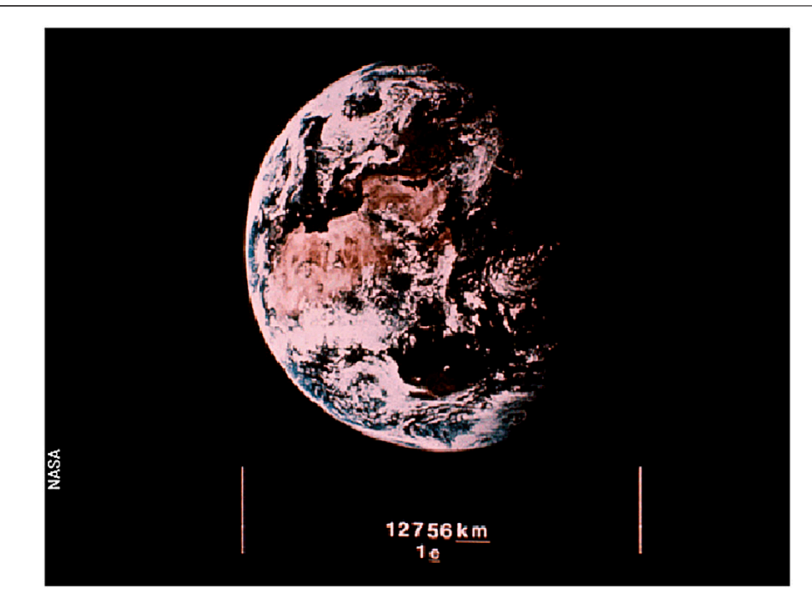

FIGURE 7 | Earth. Credit: NASA.

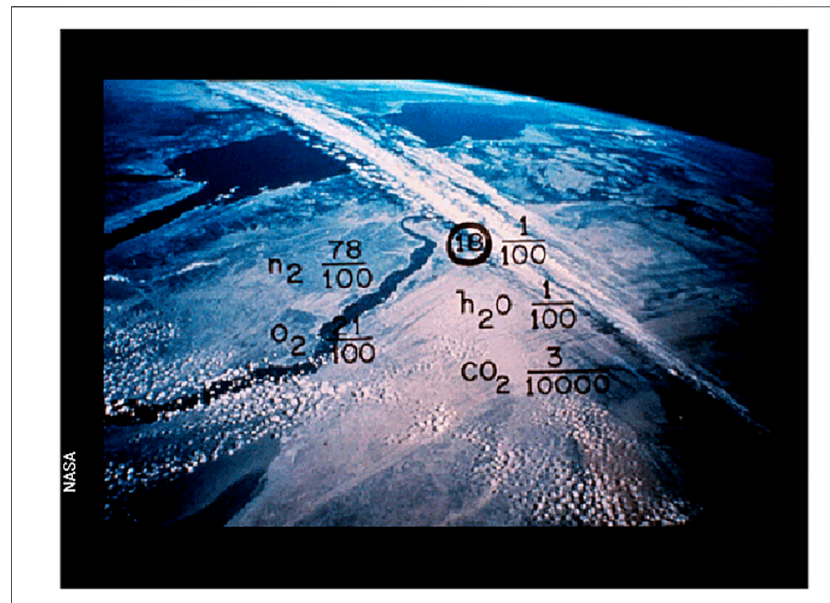

FIGURE 8 | Egypt, red sea, sinai peninsula, and the nile. Credit: NASA.

observe directly the link between the last two presented pictures. The "Diagram of family ages" shows four silhouettes of persons that were transposed from the "Family portrait" photograph. This explanatory diagram, created by Lomberg, specifies the age and weight of four family members using the numerical legends. Written in English (y for years and $\mathrm{kg}$ for kilograms), the tags introduce two children aged $4(225 \mathrm{~kg})$ and 12 years $(385 \mathrm{~kg})$, and two women aged $30(545 \mathrm{~kg})$ and 80 years $(425 \mathrm{~kg})$, indicating generation of ancestry: a mother and grandmother.

\section{THE STORY CONTINUES: NATURE, SOCIETY, AND TECHNOLOGY}

Right after the family photo follows the "Continental Drift" diagram that presents the position of continents in the distant past, present and remote future. This is a visual quote of the original informative plaque arranged by Sagan for the LAGEOS I 
Satellite (Laser Geodynamic Satellite) put in Earth's orbit in 1976, intended as a legacy for future generations of humans. The diagram opens the documentary presentation of the natural world and the environment: "Heron island," Seashore," "Snake river and Grand Tetons," "Monument Valley," "Forreste scene with mushrooms," "Fallen leaves," "Tree with daffodile." Also, the human place and activities in nature were portrayed here. The lighthouse on a seashore, the equestrian moving through sand dunes, the shepherds in Monument Valley, and the gardener raking the fallen leaves.

Picture of "Flying insect with flowers" opens the animal life section along with the diagram of the "Vertebrate evolution." This diagram, outlining the evolutionary sequence is interesting for one more reason: the male-female figures were placed at the top right of the image. Here we meet again the same pair that was displayed on the Pioneer plaques but in this Voyager diagram, it is the female representative of humankind who salutes the recipient. Coloured photos of "Dolphins," "School of fishes," "Tree toad," "Crocodile," and "Eagle" represent the biological diversity on Earth. The interactions and contact between humans, fauna and flora are again shown on several pictures such as "School of fish" (with diver), and "Jane Goodall and chimps."

Photo of "Bushmen hunters" - again with a silhouette unlocks the picture gallery of peoples from all around the world. The viewer of this spectacular slideshow can see faces of people from Guatemala, Bali, Thailand, and Turkey and their daily activities. Not only hunting, walking, working, dancing, climbing, and exercising (performance by "Gymnast"), running ("Sprinters") is portrayed in these pictures, and then teaching, learning, fishing, cooking, shopping at the supermarket, eating dinner in China. Besides activities, pictures show contacts among people, their communities (dinner, schoolroom, "Children with globe") or their interactions with the environment and animals (harvest, fishing) and with the natural world in general, such as a photograph of a diver and sea fish and a man walking in the forest.

The section dedicated to people of Earth in their natural environment fluently moves to the description of buildings and structures. Here we can observe the shift from "nature" (natural) to "technology" (artificial). The photo of the "Great Wall of China" is followed by house constructions in Africa and Amish Country, and by images of a finished house (American) and its interior. Not only buildings like the Taj Mahal and the UN centre both in daylight and at night, but also cities were incorporated into the photo gallery: Oxford and Boston. The photo of the Opera House in Sydney, the demonstration of modern architecture opens the technical part.

The story about engineering and technology starts with photos of an artisan with a drill, factory interior filled with machines, a museum exhibit, X-ray of a hand, and a woman with a microscope. An important part of the compilation is the means of transport and transportation networks - traffic jam from India, highway, jet fighter, train, Titan spacecraft (the booster rocket of both Voyagers, Figure 9), airport, and bridge. Communication engineering was not left out as we can see from the photo of the Arecibo Telescope used to transmit the first radio message to extraterrestrials together with photos of the Westerbork radio telescopes from the Netherlands.

Closing moments of the visual presentation are dedicated to photos of "Page of book" from the System of the World by Isaac Newton, an astronaut floating in space (Figure 10), "Sunset with birds," and "String Quartet." The final picture of the Golden Record's visual part is the "Violin with the music score." The photo of the musical sheet of Cavatina composed by Ludwig van Beethoven closes the visual part and opens the acoustic anthology.

\section{THE INTERSTELLAR BEST OF: SOUNDS, GREETINGS, AND MUSIC OF EARTH}

The first audio part includes twenty-one sound recordings: "Sounds of earth." The total playing time is nearly $13 \mathrm{~min}$ of various sounds. Similarly, to the picture sequence the sounds' compilation follows the chronological order and seems to favour the historical perspective. According to Sagan, some of these sounds had been present on earth since prehistoric times. The noises of volcanoes, earthquakes, thunders, mud pots and atmospheric wind, rain and surf correspond to natural phenomena. Furthermore, the record includes sounds uttered by animals: frogs, elephants, and chimpanzees, howling of hyena, barking of domestic dogs, and singing of birds. Some of the named animals were portrayed in the visual part.

The evolutionary symphony opens with beats of the first stone tools (sound of flint cracking) and continues with sounds of a blacksmith, sawing, and sheep herding (Sagan et al., 1978). The human activity of the advanced ages is represented by sounds produced by tractor, riveter, ship, train, bus, car, F-111 Flyby, and Saturn five Lift-Off. Sounds of footsteps, heartbeat, laughter, fire, speech, sound of kiss, mother talking to a child (as mentioned earlier), are documents about human life on planet earth. The last soundtrack contains the recording of electrical activity of the human brain that was transferred to sound, intended as a life sign.

The "Greetings from earth" contains spoken reports by representatives from our planet, the section includes fifty-five greetings in most spoken languages and one in a whale language. The total time of recorded greetings is about $4 \mathrm{~min}$. The shortest recording only consists of a simple "Hi!" with $15 \mathrm{~s}$ of length. The longest greeting is in Gujarati, one of the most spoken languages in India. There was no uniform choice behind the greetings composition and the speakers were given no specific instructions as to what to say (Sagan et al., 1978). The speakers were chosen on the basis of their fluency in the language. Each greeting has its inherent characteristics, possibly expressing also the common greeting formulas of the given language. Some of the greetings are recipient oriented. For example:

English: "Hello from the children of planet earth."

Swedish: "Greetings from a computer programmer in the little university town of Ithaca on the planet earth."

Czech: "Dear Friends, we wish you the best." 


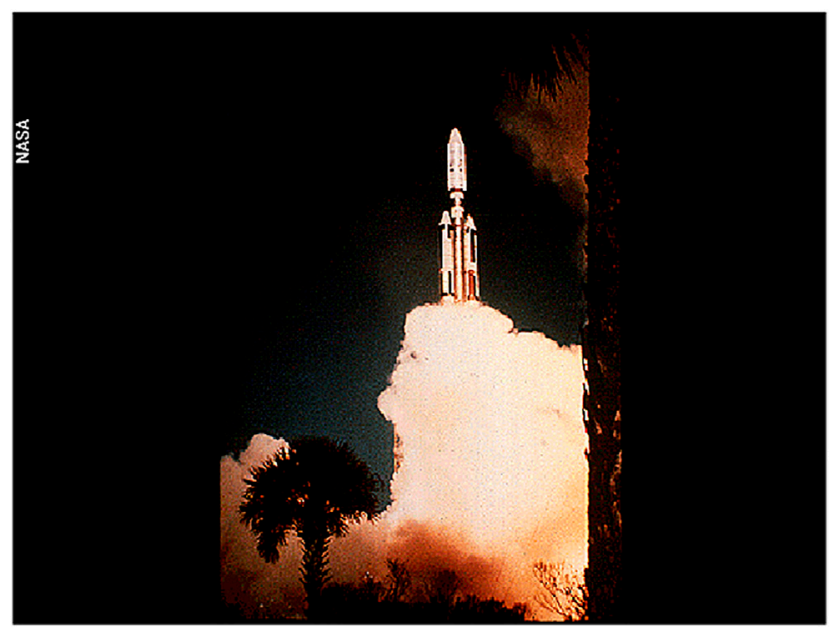

FIGURE 9 | Titan Centaur launch. Credit: NASA.

Amoy (Min dialect): "Friends of space, how are you all? Have you eaten yet? Come visit us if you have time."

Latin: "Greetings to you, whoever you are; we have good will towards you and bring peace across space."

Like the visual slide show, the third audio compilation, "Music from earth," was intended to offer the auditorium a fine terrestrial selection. Twenty-seven tracks add up to nearly 90 min of music. The musical performances include Western classical "the best of" collection, popular rock-and-roll songs, and native music typical in various geographical areas. The classical music compilation meets the high standards requirements not only on quality and popularity of music: Queen of the Night aria by W. A. Mozart, Fifth Symphony by L. van Beethoven, Brandenburg Concerto by J. S. Bach but on the reputation of interpreters and conductors (Gould, Moser, Richter, Stravinsky). The Western composers treated with partiality were Johann Sebastian Bach (three tracks) and Ludwig van Beethoven (two tracks).

The selection of music not rooted in traditions of Western culture offers a diverse and melodic set; the audience were offered Aborigine songs, Azerbaijan bagpipes, Georgian chorus, percussion from Senegal, Pygmy girls' initiation song from Zaire, Night Chant by Navajo Indians, music from Java Mexico, New Guinea, Japan, Bulgaria, China, and India with contents of the lyrics untranslated. To Beethoven is dedicated not only to the last picture of Scenes from earth but also the last track from Music from earth: Cavatine, a short and simple song that is said to be the only one piece that made its composer cry.

\section{ADAM AND EVE OF THE SPACE AGE}

The controversial engraving of a naked earthling pair provoked much discussion and caused public indignation (Havel 1996). The ambivalent reactions of the public on the Pioneer plaque together with the copyright restriction appear to be the reasons why the public were not informed about the final contents of the Golden Record until the moment the Voyagers were safely put

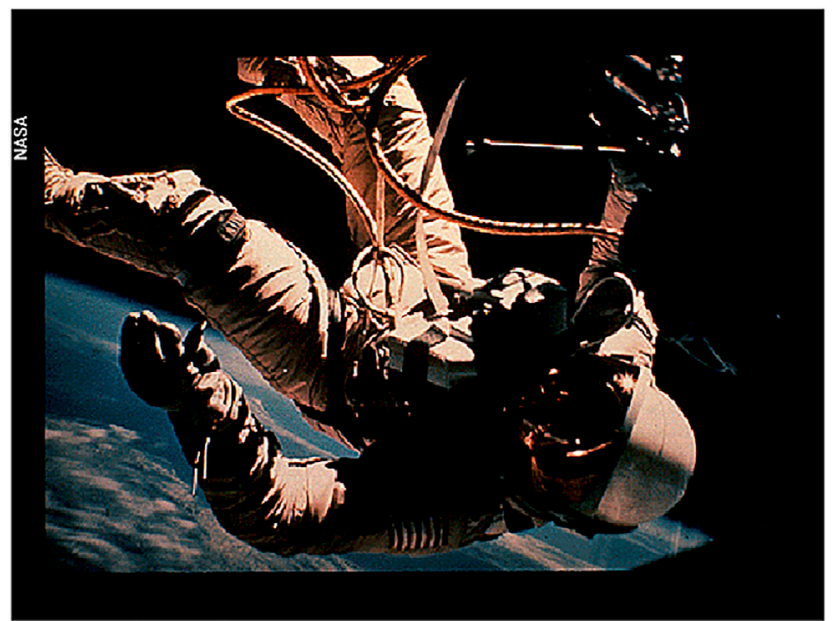

FIGURE 10 | Astronaut in space. Credit: NASA

beyond earth's orbit. Despite the initial public reaction, this image has become a symbol of the active search for life beyond earth and to this day continues to be one of the visual icons of the Space era.

The significance of the "couple of Earthlings" is also illustrated by the reuse of the very same representation in other messages, such as the Cosmic Call radio message. While Pioneer and Voyager are the material objects, manufactured messages attached to a spacecraft as a plaque, plate, or record; the second method of sending messages to outer space is radio broadcast. A "radio message" is a signal transmitted by a radio telescope. The transmissions are often referred to as a more efficient method of search for extraterrestrial intelligence because the signal travels at the speed of light, the maximum known velocity. The historically first radio signal aimed at another civilisation left earth in 1974 from the large radio telescope in Arecibo, Puerto Rico, a part of the National Astronomy and ionosphere Centre (NAIC), designed by Drake.

The visual quote of Pioneer's greeting couple (Figure 11) can be found in the opening of the Cosmic Call radio message written by Canadian astrophysicists Yvan Dutil and Stephane Dumas and first broadcast in 1999. The Cosmic Call message was intended to be an update of the Arecibo message and therefore is larger in size, duration, and scope. The original twenty three pages long Cosmic Call one was updated 4 years later. The message contained photos, drawings, audio and video files that were submitted by the Team Encounter members worldwide, and in 2003 rebroadcast again. The images below present the Adam and Eve of the Space Age as portrayed on the original Pioneer Plaque (1972) and Cosmic Call in 1999 (and 2003) (Figure 12).

The figures of human procreation are well debated in academic literature, popular media, and academic publications. While they were intended to present representatives of Earthlings, they can be seen as a clear manifestation of $1970 \mathrm{~s}$ Western normativity as far as gender, ethnicity, and sexuality are concerned. The human bodies as well as the sexes are portrayed within conventional and stereotyped understanding the sexual dimorphism and fixed into idealised form without any 


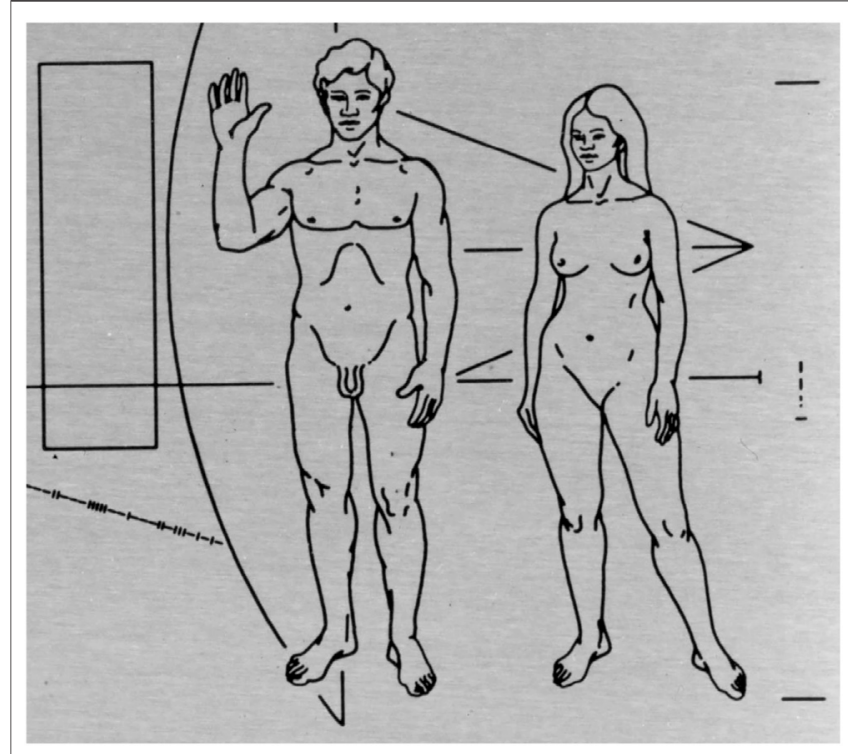

FIGURE 11 | The detail of Pioneer Plaque, the greeting couple of Earthlings. Credit: NASA.

abnormalities. Presented also on the Voyager Message in 1977, this variation of the procreation couple, described by Michael Warner in the introduction to the "Fear of Queer Planet" as a clear manifestation of "heteronormavity" (Warner and Collective 1993: xxiii). The story of life is presented in a rather utilitarian fashion with biology, uniformity and function being preferred over culture, variety and context. For example the cultural context of reproduction that is the institution of marriage, was missed out too.

The enduring American cultural icons, the messages continue in their pioneering voyage through interstellar space and terrestrial media and art alike. They did not escape the attention of science fiction writers, notably the closing scene of the 1979 full-length Star Trek: The Motion Picture (Star Trek, 1977). At the end, a superior extraterrestrial being returns the Voyager probe (V-GER) to its home planet with its message unread.

The messages can be also viewed from another perspective and that is their biblical allusion and mythological significance. In the case of the Pioneer and Voyager (and Cosmic Call) messages, the duality of sexes was pointed out, and the Voyager message presents a narrative about what makes humans human, the life events and activities inherent to humanity. Berger in his study of narratives in popular culture analysed the symbolism and mythical aspect of the Apple Inc. 1984 commercial and in particular the Apple logo, a study that gives an interesting parallel to how to interpret the interstellar story (Berger, 1997). Berger argued that the logo "also has an intertextual and in this case mythological significance, because it also alludes to Adam and Eve in the Garden of Eden" (1997:119). The Pioneer Plague and Voyager Record, both carry an image that when approached in terms of its intertextual connections can be interpreted as a creation story. In this context the mythological aspect of the image of

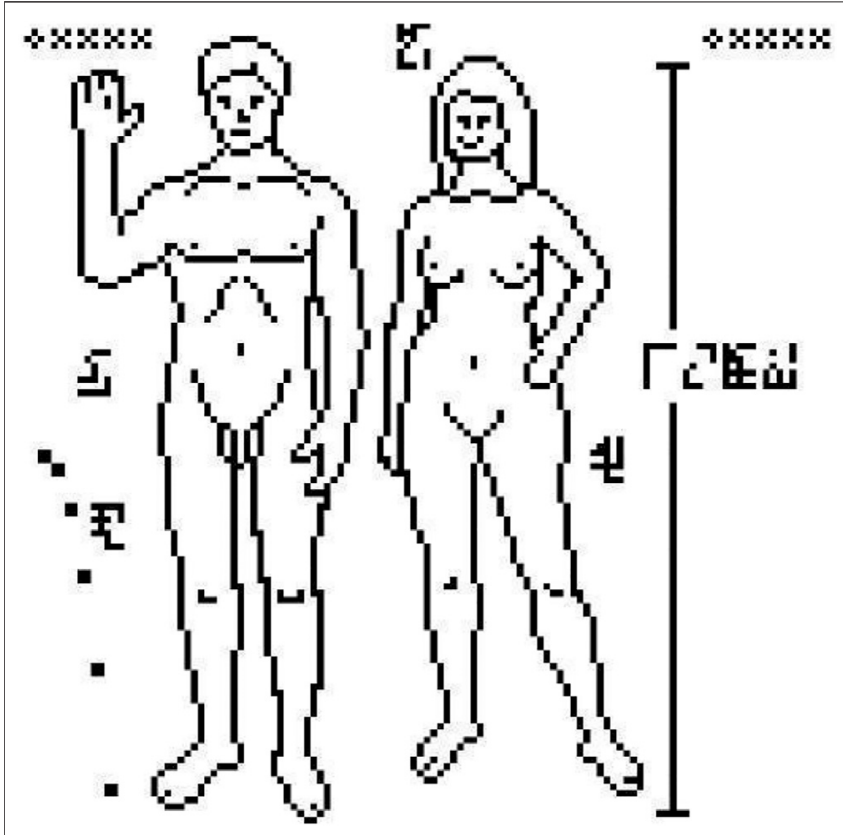

FIGURE 12 | The greeting couple, Cosmic Call (1999). Credit and Copyright: Y. Dutil, S. Dumas.

the couple, the biblical allusion of Adam and Eve, here in the center of a Space age narrative (Capova, 2013).

Even today the legacy of Voyagers lives on. To celebrate the 40th anniversary of Voyager 1's launch, NASA launched a space social media campaign using Twitter, Instagram, Facebook, Google + or Tumblr. The public were asked to submit a brief and uplifting text tagged as \#MessageToVoyager. The winning messages selected by popular vote were beamed towards Voyager one into interstellar space on August 5, 2017. The Star Trek star William Shatner, known as Captain Kirk of the Starship Enterprise assisted with the broadcast.

\section{THE COMMONALITIES}

The symbols of neutral hydrogen as a universally recognisable constituent of the Universe, the map locating earth using near and recognisable stellar objects, the procreation couple greeting the extraterrestrials-it all presents a story. We have seen that the images were used to convey information, to explain and to interpret. Sounds, spoken word and music as an alternative to diagrams and photos seems to have a specific role in the message design. Similar to written language, musical notation or a music sheet can be reproduced by anyone who knows how to read and interpret the symbols.

Science was set as the preferred universal language and for decades to come also became a blueprint of interstellar communication. A good example is the model of neutral hydrogen. The time-period measurement is explained using the period associated with the fundamental transition of the hydrogen atom that provides the basic time reference. The 


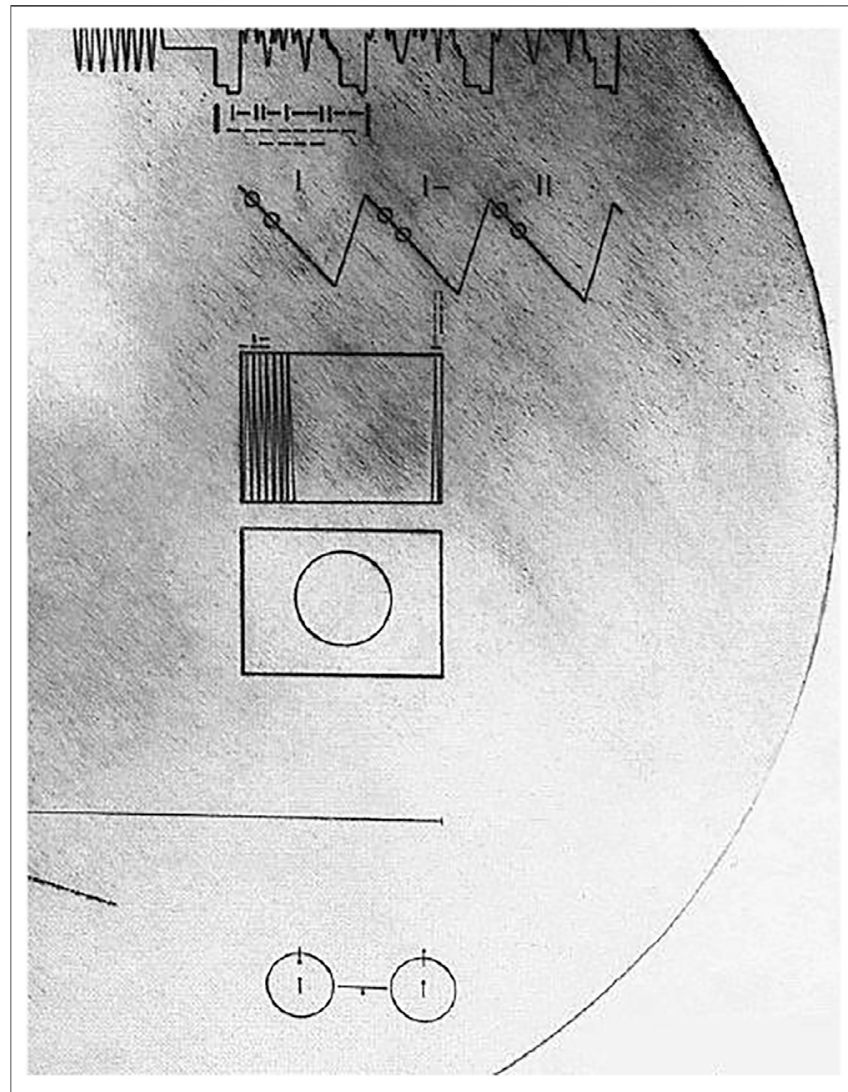

FIGURE 13 | The Pulsar Map and Hydrogen Symbol. Segment of the Voyager message inscription (1977). Credit: NASA.

hydrogen symbol is accompanied by the location of earth, both adopted from the Pioneer plaque. The map is created by using the neighbouring rotating stars that emit electromagnetic radiation known as pulsars, to locate our planet within the galaxy. The images below illustrate that the hydrogen clock and pulsar map symbols were presented on the Voyager protective cover (Figure 13) and Pioneer plaque (Figure 14).

Numbers were proposed as a language suitable for interplanetary and later interstellar communication, or as Samuels described it: "a lingua franca for this communication" (Samuels 2005). We can also evaluate the concept of the other lifeforms or receivers of the messages - advanced, scientific, extraterrestrial civilisation (Capova 2008) that possesses the same "shared codes" (Samuels 2005).

The time reference points to another important characteristic of the story of humanity and that is the ascending tendency within linear understanding of time. The perception of time among different cultures has been studied by anthropologists who highlighted the differences in understanding the time. Namely, the cyclical conception of time as a perpetual repetition corresponding to seasonal rhythms. The role of the ritual circle on Hawaii Islands was described by American cultural anthropologist Marshall (Sahlins, 1981). Or Balinese concept of time and calendared system studied by Clifford (Geertz, 1973), who discovered the varieties in actual day length that imply the

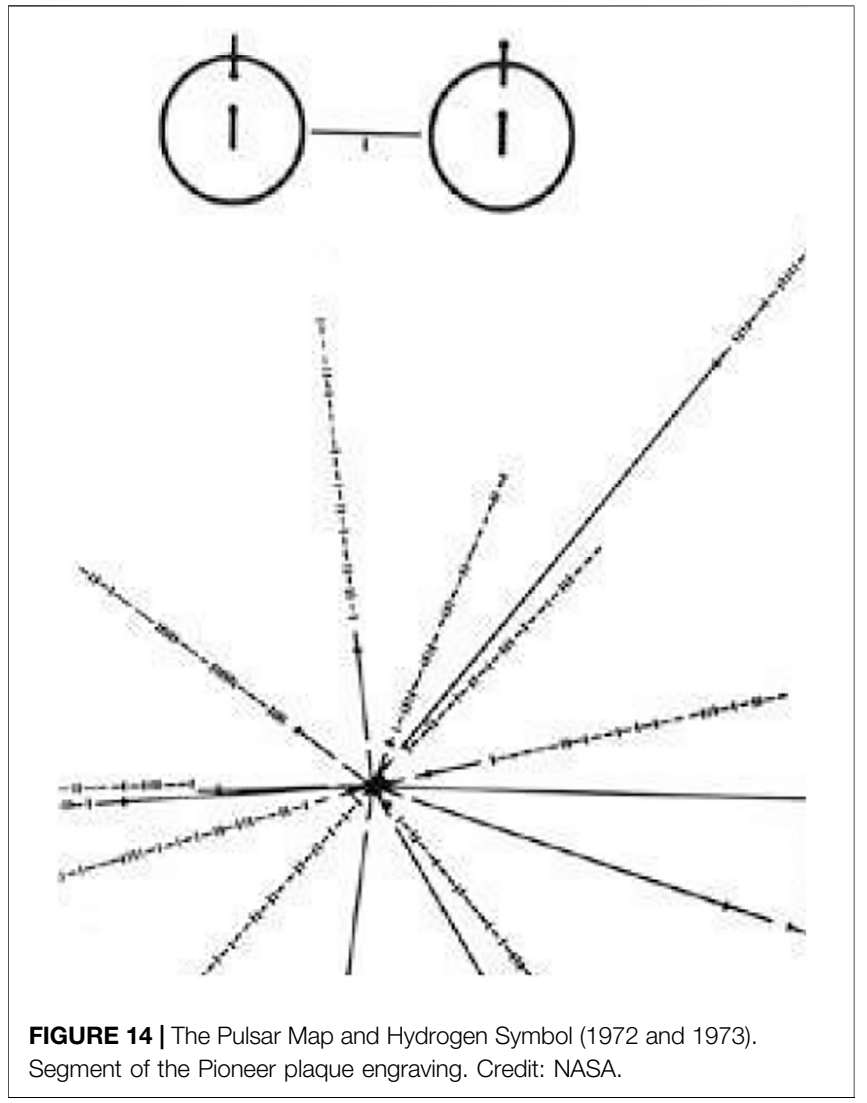

different concept of duration and flexible units of time. Also, the Scenes from earth proceed as a series of events that are leading towards something: from the basics to the diversity, from the wild nature to technological development; the idea of progress.

The social studies of science and technology and philosophy of science have described the role of sciences as fundamental pillars of recent Western development and out of which also emerge the key values: rationality, empiricism, secularity, and the idea of continuous progress (Schech and Haggis 2000). The light of reason as a basis of scientific deliberation is a core scientific value and a principal inheritance of the Enlightenment, a European intellectual movement of the late 17 th and 18th centuries emphasizing reason and individualism rather than established doctrines.

The Voyager's story of life was told along the developmental line with its main plot being advancements, technological development, science, knowledge of concepts of laws of the Universe, all described by languages of contemporary science. Of course, the message design is based on two unavoidable assumptions. First is the biological constitution of the receiver who possesses the capability to perceive and investigate, or is curious about what the messenger floating in space has to say about its senders. Second is the intelligence, or intellectual constitution that is shaped by a contemporary Western type of science education. In other words, the extraterrestrial lifeform has to have a sense of sight that facilitates the visible or "seeing," and the sense of hearing that facilitates audibility or "hearing" and "listening." The receiver is a priori burdened with the human qualities of the physical body, with a brain producing an intellect; 
and sophisticated and organised knowledge of the physical and natural world, that is science. The extraterrestrial being is required to see, hear, think, read, interpret, and understand (Capova, 2013).

\section{INTERSTELLAR MUSEUM EXHIBIT}

Let us suppose that the content of the Voyager message can be viewed like a museum exhibit. We have just finished a walk through this museum that exhibits colourful photos and cultural artefacts from the American era of the $1970 \mathrm{~s}$. The collection on display, accompanied by fine musical selection played in the background, originates from various, yet not recognised places and peoples. As the visitors walk through the museum, they read the "legends" attached to each of the pictures that give information about the exhibit, about its place of origin, their dating, history, and supposed use. At the end of the exhibition, the visitor may be fascinated by the wonderful diversity of nature and cultures and feel enthusiastic and overwhelmed by the extent of the exhibition. Some visitors may think that the museum contains sufficient information about our world, but others may consider the following.

First, the compilation itself is not extensive enough, inevitably there were many "photo exhibits" left in the museum depository simply because there is not enough space to display them all. Despite attempts to describe "life" there is one thing that was missed out entirely. The Golden Record does not contain any relevant information about dying and death. There are indications of this basic fact of all life (e.g., hunting, eating), yet without mentioning the fundamental fact of life, the message paradoxically cannot claim itself to be a complete story of human life. The message does not refer to any negative characteristics of humankind such as conflicts, hostility or war. The idealised part of humankind was demonstrated intentionally in order to present "a hopeful rather than a despairing view of humanity and its possible future" as Sagan explained (1978). For this reason, no references to war or conflict were mentioned either. The Voyager message shows only positive values, knowledge and progressive development of contemporary Western or scientific society.

Secondly, references to religious or spiritual life and/or ritual behaviour have been entirely excluded from the human story other than indirect symbolics and possibly also the role of music. Given the undebatable presence of religious and spiritual beliefs in human societies, it is a question why such a crucial aspect of human life has been omitted entirely? One explanation could be that the dominating view - the one of science - was the deciding factor to omit religion and religious considerations, in favour of scientific rationality and secularity.

The third point is quite simple. The contents selection was unavoidably biased by the Voyager committee, by their expertise,

\section{REFERENCES}

Berger, A. A. (1997). Narratives in Popular Culture, media, and Everyday Life. Thousand Oaks: Sage Publications.

Capova, K. A. (2013). The Charming Science of the Other: The Cultural Analysis of the Scientific Search for Life beyond Earth, (PhD Thesis). UK: Department of Anthropology, Durham University. professions, and even by their beliefs about the nature of our lived world. For this reason, the life story offers more than just a mere description of "life" but also the interpretation of what "life" consists of. Not only the photographs and diagrams but also the use of several definitions (mathematics and chemical formulas as conventional designations) underline the rational understanding, scientific description of the world as the basis of the content selection inscribed scientific knowledge (Macauley, 2006). Science is regarded as the universal language, even in the case of interstellar information relay.

The messages are period pieces. As a product of their era, they have faithfully captured the thinking, knowledge and even scientific paradigms of their era. One example of such a paradigm and its shift in case of astronomy can be seen in Drake's representation of the Sun with nine planets. In 2006, the International Astronomical Union, drafted a new definition of a planet and consequently decided by vote that Pluto does not meet the requirements for a planet. That means that the scientific paradigm has changed and the Solar System currently consists of eight planets. As a consequence, the model of our star system placed on Voyager probes is no longer considered a valid paradigm.

Rather than offering mere criticism of choices made by the Voyager committee, or proposals of what should have been sent, this brief analysis concludes with an invitation to understand the Voyager message as a linear narrative of human curiosity presented by a small group of people who took on the challenge to present our world to unknown receivers.

Loyal to their disciplinary boundaries, the committee members have, rather than the variety of lives and cultures on earth, presented a success story of contemporary Western societies and its sciences. As Sagan rightly noted, different people in different points in history would have made different choices. And their choice was to send this description of what life meant to them at that time - a colourful scientific mosaic of life on earth frozen in time.

\section{DATA AVAILABILITY STATEMENT}

The original contributions presented in the study are included in the article/supplementary material, further inquiries can be directed to the corresponding author.

\section{AUTHOR CONTRIBUTIONS}

KAC has written this based on her MA and PHD research.

Capova, K. A. (2008). The Voyager Message, (MA Thesis). Prague: Department of General Anthropology, Charles University.

Daston, L., and Galison, P. (2007). Objectivity. New York: Princeton University Press. Geertz, C. (1973). The Interpretation of Cultures: Selected Essays. Basic Books. Havel, I. M. (1996). Jsme Tady Taky! (We Are Here Too!). Vesmir 303 (6).

Macauley, W. R. (2006). Inscribing Scientific Knowledge: NASA's Pioneer Plaque and the History of Interstellar Communication, 1957-1972. (MA Thesis). Faculty of Life Sciences. University of Manchester. 
NASA JPL Golden Record:. Available at: https://voyager.jpl.nasa.gov/goldenrecord. (Accessed September 21, 2021).

NASA Pioneer Mission. Available at: https://www.nasa.gov/mission_pages/ pioneer/index.html. (Accessed September 21, 2021).

NASA (1977). Pioneer Odyssey. NASA Scientific and Technical Information Office, 349/396. USA: NASA, Scientific Publication.

NASA Voyager Mission. Available at: https://voyager.jpl.nasa.gov (Accessed September 21, 2021).

Sahlins, M. (1981). Historical Metaphor and Mythical Realities. Ann Arbor, MI: University of Michigan Press.

Sagan, C., Drake, F. D., Druyan, A., Ferris, T., Lomberg, J., and Salzman Sagan, L. (1978). Murmurs of Earth: The Voyager Interstellar Record.

Sagan, C., and Drake, F. (1975). The Search for Extraterrestrial Intelligence. Sci. Am. 232, 80-89. doi:10.1038/scientificamerican0575-80

Samuels, D. (2005). "Alien Tongues," in Culture. Anthropology in Outerspaces. Editor D. Battaglia (Durham: Duke University Press). doi:10.1215/9780822387015-003

Schech, S., and Haggis, J. (2000). Culture and Development: A Critical Introduction. Oxford ; Malden, MA: Blackwell Publishers.

Star Trek (1977). The Motion Picture Directed by Robert Wise. Created by Gene Roddenberry. USA: Paramount Television.
Warner, M., and Collective, S. T. (1993). Fear of a Queer Planet: Queer Politics and Social Theory. University of Minnesota Press.

Conflict of Interest: The author declares that the research was conducted in the absence of any commercial or financial relationships that could be construed as a potential conflict of interest.

Publisher's Note: All claims expressed in this article are solely those of the authors and do not necessarily represent those of their affiliated organizations, or those of the publisher, the editors and the reviewers. Any product that may be evaluated in this article, or claim that may be made by its manufacturer, is not guaranteed or endorsed by the publisher.

Copyright $(02021$ Capova. This is an open-access article distributed under the terms of the Creative Commons Attribution License (CC BY). The use, distribution or reproduction in other forums is permitted, provided the original author(s) and the copyright owner(s) are credited and that the original publication in this journal is cited, in accordance with accepted academic practice. No use, distribution or reproduction is permitted which does not comply with these terms. 